\title{
From the Physical Restoration for Preserving to the Virtual Restoration for Enhancing
}

\author{
Elena Nencini and Giuseppe Maino \\ Faculty of Preservation of the Cultural Heritage, University of Bologna, \\ Ravenna site, 5, via Mariani, Ravenna, Italy \\ e.nencini@gmail.com, giuseppe.maino@unibo.it
}

ENEA: Italian National agency for new technologies, Energy and sustainable economic development, 4, via Martiri di Montesole, Bologna, Italy

giuseppe.maino@enea.it

\begin{abstract}
Digital image processing techniques are increasingly applied to the study of cultural heritage, namely to the analysis of paintings and archaeological artefacts, in order to identify particular features or patterns and to improve the readability of the artistic work. Digital or 'virtual' restoration provides a useful framework where comparisons can be made and hypotheses of reconstruction proposed without action or damage for the original object, according to the adopted general rules for practical restoration.
\end{abstract}

Keywords: Geometrical distortion, image enhancement, virtual restoration, mosaics, cultural heritage.

\section{Introduction}

The cultural heritage field has undergone profound changes in recent decades, linked to an increasingly demanding public, but also to the transformation of culture in a real 'good' that can generate wealth and employment. The computer expert that can manage virtual restoration programs as now joined the more traditional professional figure of the restorer, in a still experimental way.

These are applications that, in this specific field, provide a number of interesting proposals: the virtual restoration does not act on the art work, but simulates a visual and aesthetic improvement of the work, so enhancing it. It also gives the possibility to choose a series of solutions, before technical operations.

The case study object of this paper is an experimental project of virtual restoration carried out on a mosaic from the church of San Severo in Classe, near Ravenna. The construction of San Severo dates from the late sixth century, was consecrated in 582 and was pulled down and abandoned in the early '20s of the XIX century. The floor of the church was formed by a rich mosaic, which was only partially found.

At the end of the 1966 excavation campaign, a mosaic carpet - 4.50x2.75 m-was discovered at the center of the main nave. This mosaic showed a grid of rows of tangent pised square containing figures of birds made of glass paste, of great elegance and extremely naturalistic; around this main schema runs a shaded three strand guillocheon on a black ground (see fig.1). 
The mosaic was found at a height of $0.40 \mathrm{~m}$ beneath the floor of the church, almost in the middle of the main nave, but unlike all the other mosaics, it was not aligned and oriented north to south direction. These data have suggest that it might be connected to an ecclesia domestica, an oratory that might have been part of the Roman domus, whose remains are beneath the church. A place of great devotional importance, perhaps, the place itself where the saint had exercised (carried out) his apostolate.

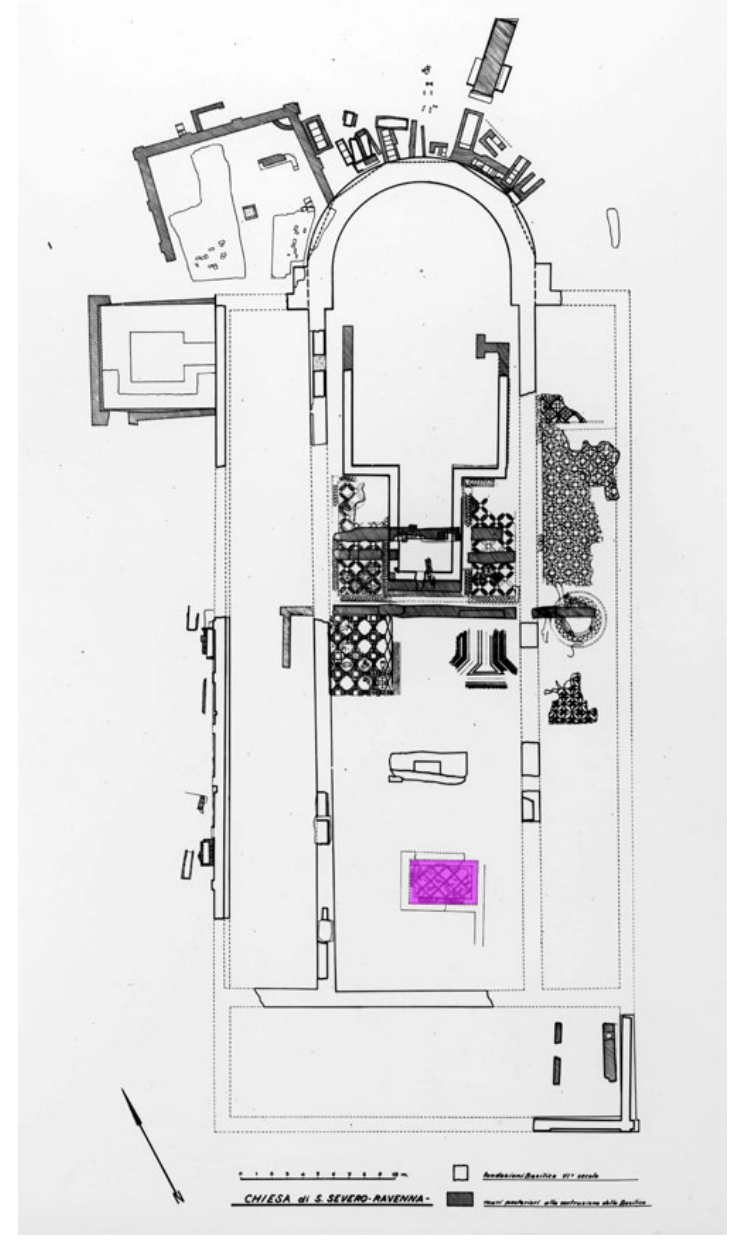

Fig. 1. Plan of the San Severo church. The original location of the mosaic considered in this work is represented by the rectangle in the lower part of the building, near the entrance.

Today the floor, lifting and relaiding on cement mortar in the late 60s of last century, is at the Museo Nazionale in Ravenna, divided into two sections, placed far apart on a wall in a narrow and dark lobby, as shown in fig. 2. 

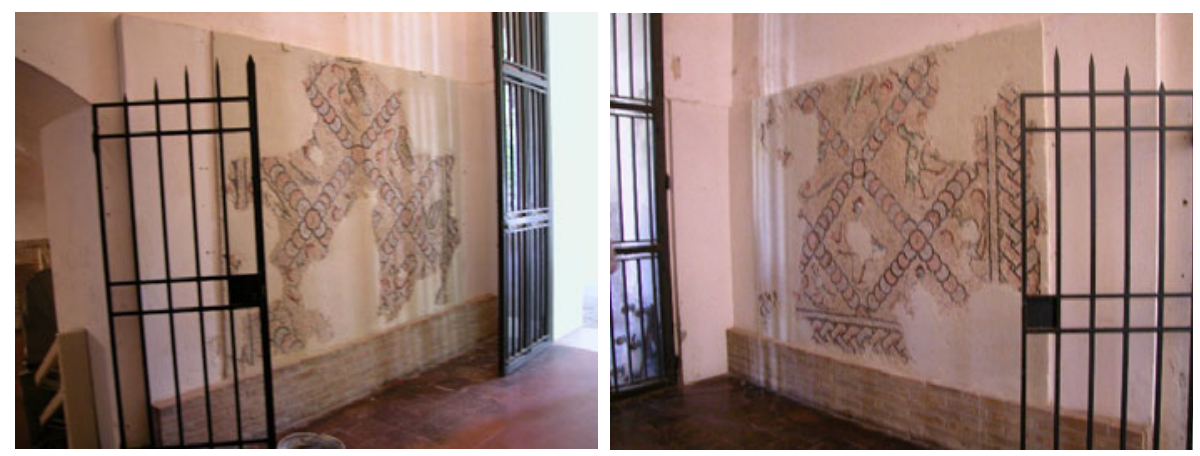

Fig. 2. The actual location of the San Severo mosaics

The verticality of the mosaic, the separation of the two sections decontextualize the mosaic and impoverish it of its original function as an integral part of the internal architecture of the basilica.

Precisely for this reason it was decided to opt for a virtual restoration project, with the intent to provide guidance for future restoration and to revalue this art piece. The characteristics of many mosaics - the symmetry and the repetition of geometric patterns - make them suitable for the use of information technology both for a simulated integratiom and for the reconstruct by analogy of the geometric pattern. The use of computers and image processing programs can, in fact, offer a preview of the restoration, that can direct the restorer in the techmical operations.

\section{Virtual Restoration}

Our virtual restoration project started from the idea of bringing together the two sections. In order to deal with a virtual restoration it is necessary to have the images scanned at high resolution; the photographic documentation was made with a Nikon D90 at 300 dpi resolution and Kodak color reference band.

We have chosen the two images that were considered the best for color reliability and for minor distortion, since the narrowness of the environment did not allow a clear global frontal view of the entire floor.

It was then necessary to eliminate the perspective and bring all images in 1:10 scale. To this end we used a simple photo editing program such as GIMP, which was also used for all subsequent operations. As a matter of fact, we used very simple and easily provided software to perform this work since our purpose was to give an example of virtual processing useful for conservators and restorers as well as for scholars (archaeologists, art historians, etc.) that can be carried out without specific expertise and computer skills.

After the images were acquired in digital format, we were able to proceed with the actual reconstruction of the floor, taking into account the geometric motifs that make up the mosaic assembly and that made the recomposition the most reliable. It was not possible to use excavation maps as they had no metric references at all. 
Once we had a basic image we went on to reconstruct by analogy the geometric motif of the floor, which covered both the outer frame with its shaded three strand guillocheon, as well as the internal allocation of the carpet, formed by a grid of partly overlapping circles, in alternating colors.

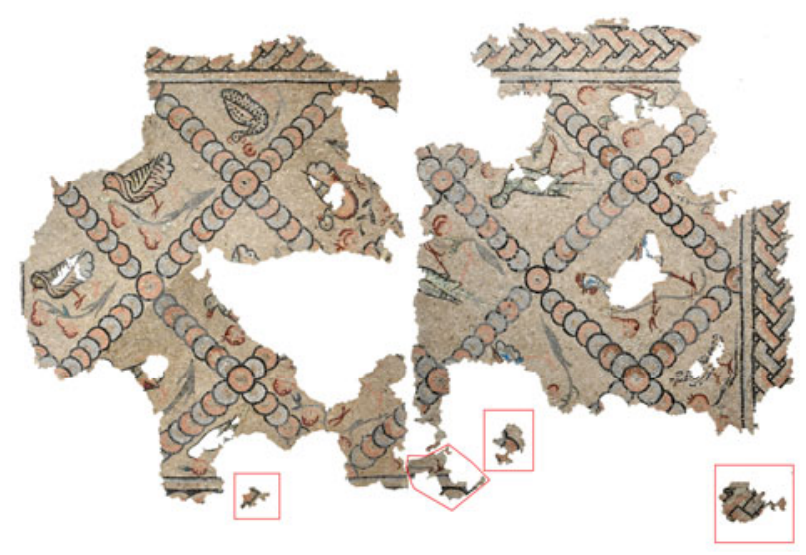

Fig. 3. Front image of the two mosaic fragments; the parts inside rectangles refer to fragments mistakenly placed in the museum relocation

Once the virtual reconstruction was completed, some fragments of the mosaic did not fit perfectly, this probably because of injuries and of deformations caused by the tearing up and repositioning the mosaic on mortar support, therefore small corrections were needed, with minimal and calibrated geometric modifications (fig. 4).

In addition to the reconstruction of geometric patterns, shown in fig. 5, a proposal was made concerning the integration of the figurative lacunae that are not reinstated, consisting of three tables.

The lacunae have been reintegrated, respectively:

- with a neutral color;

- with a deliberately discordant color;

- with a camouflage integration.

These different choices are shown in figs. 6-8 and make an evaluation possible of the obtained results from an aesthetic and conservative points of view.

The virtual restoration offers a number of possibilities in the field of mosaic restoration, although to this date it is not yet so widely adopted. In the case under consideration - the Gallinelle mosaics - it allowed, at low cost and with great ease, to create a graphic reconstruction of the mosaic floors, so that when a conservative restoration will be carried out, the restorers will have more significant information and different solutions for the integrations. In addition, the handling of mosaic fragments - often very bulky and made heavy by concrete support - certainly does not not make easy delicate operations such as recompositions. 
But the virtual restoration not only offers to restorers the possibility of recomposing a floor: it also provides the opportunity of simulating on the digital image with a photo editing program, the type of integration and the color so that scholars, restorers and conservators may evaluate the final appearance of the work and the different aesthetic choices.

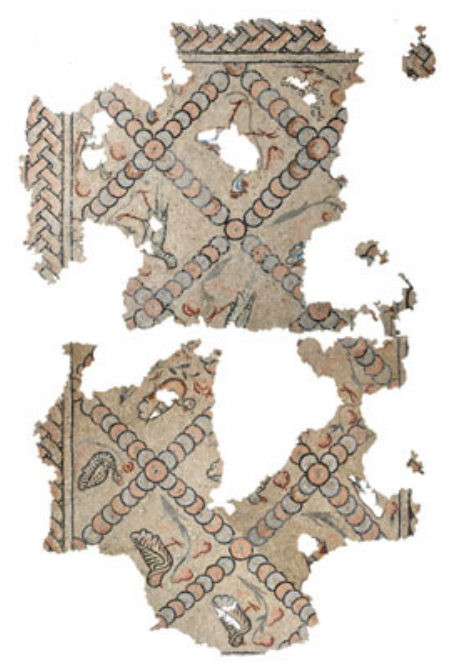

Fig. 4. Front image of the two mosaic fragments where the smaller pieces have been placed in the correct positions

\section{Concluding Remarks}

The virtual restoration is also an essential tool for the revaluation of cultural heritage. The new kind of consumer must in fact find the most suitable means to understand what she/he sees. A mosaic floor with large lacunae may in fact resemble a ruin rather than remind the magnificent mansions that it had been part of. Therefore a mosaic floor, decontextualized, hung on a wall and with large lacunae deprives the visitor of vital information.

The virtual restoration then, at very low cost, may intervene by proposing the reconstruction of the entire floor, thus playing an important didactic role and giving back to the mosaic its readability. In the case of the Gallinelle's mosaic, split in two fragments, attached on a wall in a dark, narrow room, the visitor can not understand its importance: she/he, certainly, can not imagine that same floor within the church where its position probably indicated an important ancient worship area. 


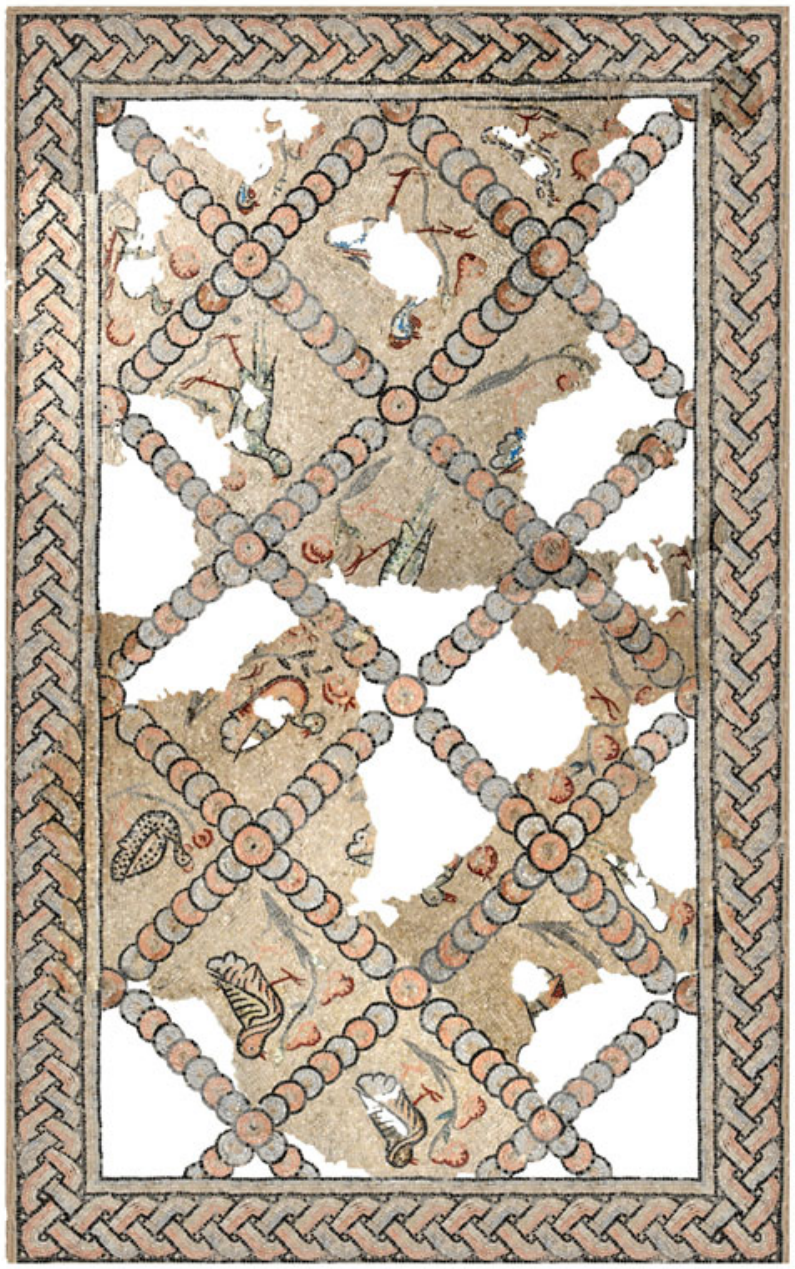

Fig. 5. The mosaic with virtual reconstruction of the geometric motifs

In this case the presence of the digital reconstruction of the floor with camouflage mimetic integration could to revalue the importance of this mosaic floor with its delicate birds, made more precious by the glass tesserae, and give back, albeit partially, its integrity and dignity as a work of art, while waiting for the conservative restoration. 


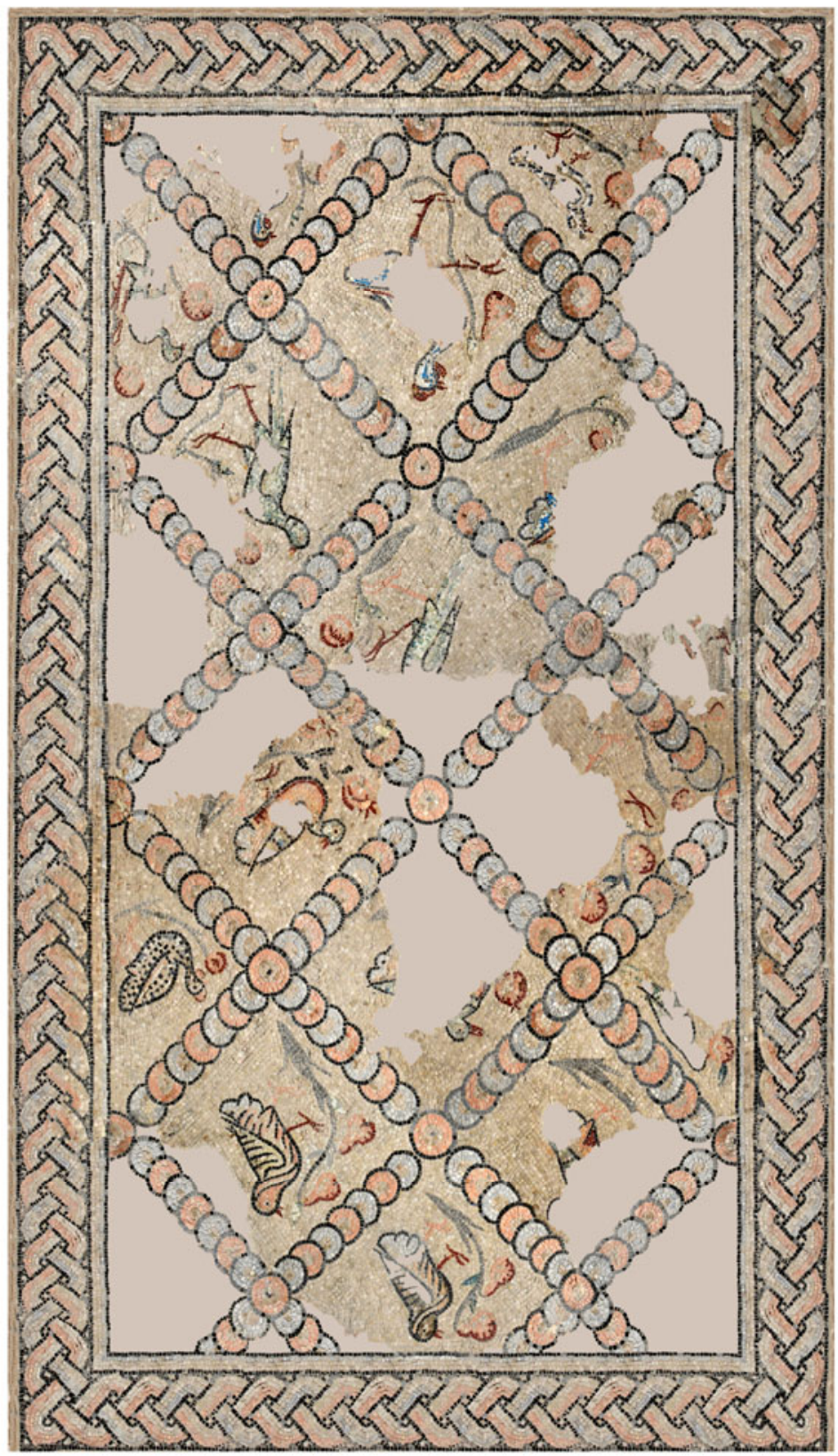

Fig. 6. The 'restored' mosaic with neutral color integration 


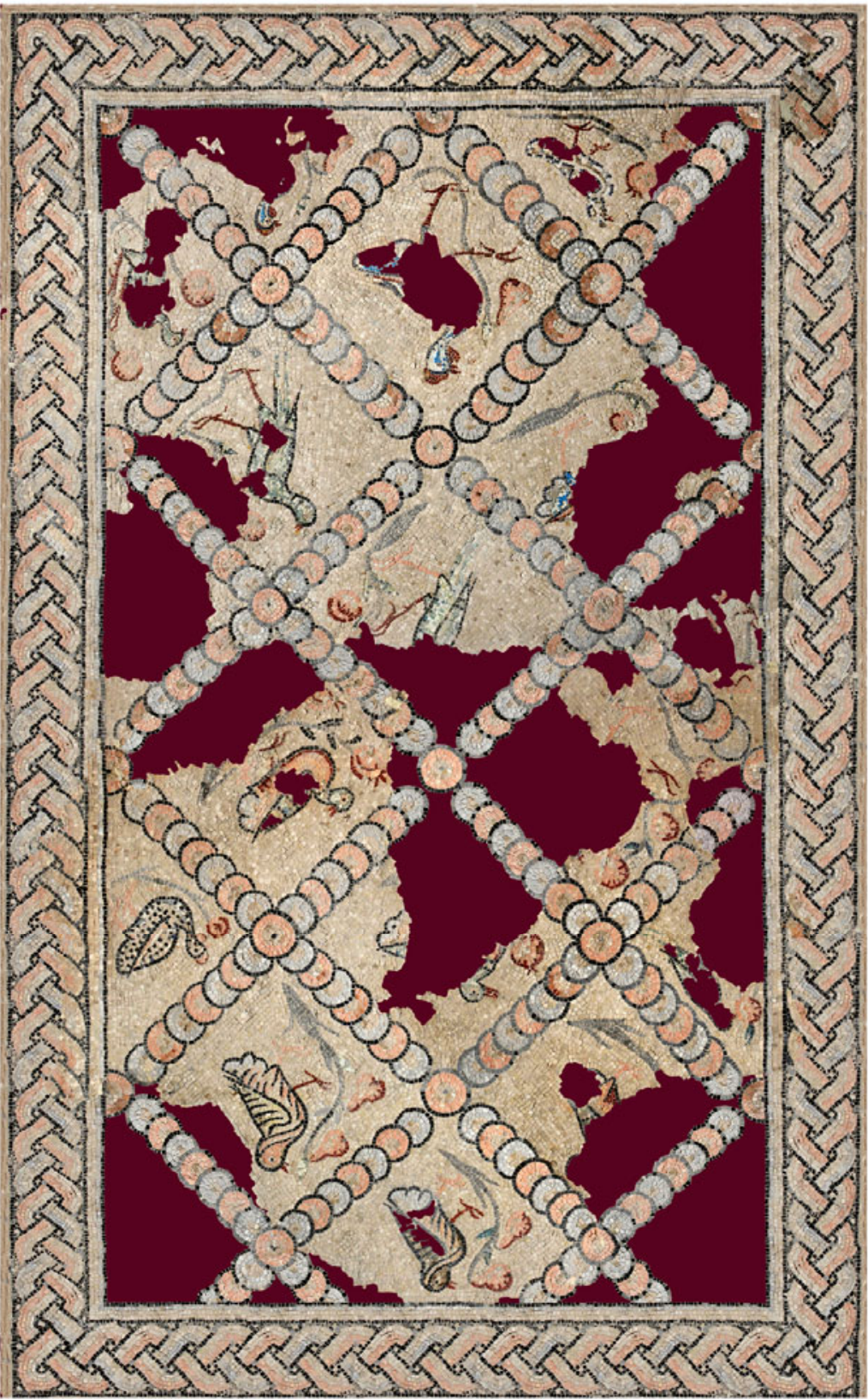

Fig. 7. The 'restored' mosaic with discordant color integration 


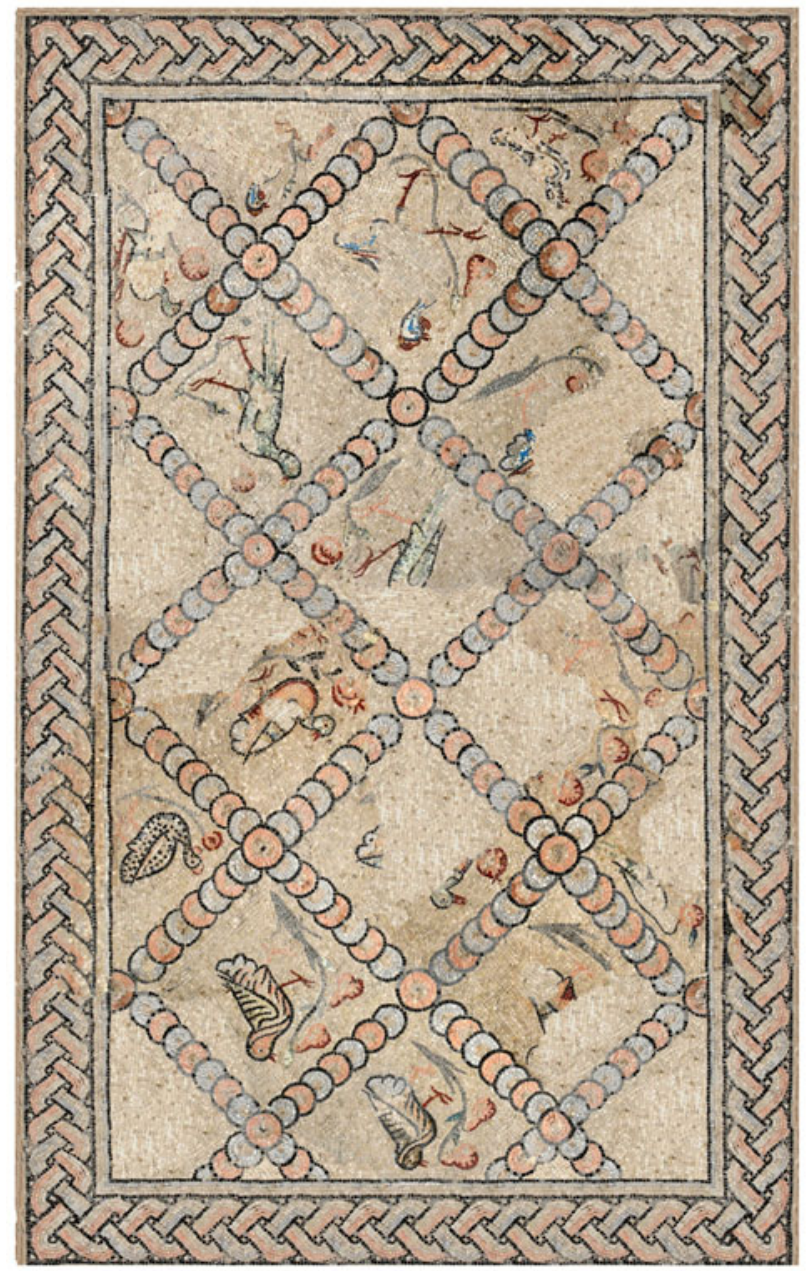

Fig. 8. The virtually restored mosaic with camouflage integration

The case subject of this work highlights the importance of a preliminary study, as a preparation of a restoration before performing surgery. But the virtual restoration not only offers the possibility to the restorer of reconstructing a mosaic: It also offers the ability to simulate on suitable digital images, by means of a photo editing program, the type of integration and the relevant color. Therefore, scholars, conservators and Superintendents can evaluate the final appearance of the work and the different aesthetic choices.

In the case of fig. 7, for example, we deliberately chose a red-violet great impact in order to emphasize the integration. In the words of Cesare Brandi - the first director of Italian National Institute of Restoration - the color of integration must be reduced to the background level and should not compose directly with the color distribution of the surface of the work (as seen in fig. 8). 
Last but not least, the virtual restoration is an essential tool for promotion of cultural heritage. In the face of increasing and diverse audiences with different levels of cultural education, museums and archaeological sites seek more and more to create accurate and comprehensive educational courses. The new user should in fact find the most appropriate ways to understand what sees.

A mosaic floor with large gaps may well resemble a ruin rather than refer to the magnificent mansions for which it had been made. The mosaic floors were, in fact, in the Roman domus as well as later in churches, closely related to architecture and function of rooms: The 'triclinium, for example, i.e. the floor space that would house the beds had no drawing, while, at the center, was placed an emblem or a representation, positioned so as to be watched by the landlord and the guests when they were eating. In every room, then, the drawings of the floor were turned towards the entrance, to be admired by those who entered. Then the virtual restoration, with a very low cost, may intervene proposing the reconstruction of the entire floor, thus playing an important educational function and returning to the mosaic readability.

\section{References}

1. Russ, J.C.: The Image Processing Handbook. CRC Press, Boca Raton (1999)

2. Brandi, C.: L'Istituto Centrale del Restauro in Roma e la Ricostituzione degli affreschi. Phoebus I(3/4), 165-172 (1947); idem, Il Mantegna ricostruito. In: L'Immagine 3, 179-180 (1963); idem, Teoria del Restauro, Milan (1984)

3. Maioli, M.G.: La basilica di San Severo a Classe, scavo e architettura. In: Santi, Banchieri, Re. Ravenna e Classe nel VI secolo. San Severo il tempio ritrovato, Milan (2006)

4. Racagni, P.: Del distacco dei mosaici e della loro conservazione. In: La basilica ritrovata. I restauri dei mosaici antichi di San Severo a Classe, Ravenna, Città di Castello (2010) 